To cite this Article: Juvonen, S. ; Nurkka, P. \& Väkeväinen, K. (2017) Experiences of Cooperation between a Higher Education Institutions and Industry and its Impact on Working Culture. INTED2017 Proceedings, pp. 8632-8637.

DOI: $10.21125 /$ inted.2017.2048

URL: https://library.iated.org/view/JUVONEN2017EXP 


\title{
EXPERIENCES OF COOPERATION BETWEEN A HIGHER EDUCATION INSTITUTION AND INDUSTRY AND ITS IMPACT ON WORKING CULTURE
}

\author{
Sanna Juvonen, Pauliina Nurkka, Kyösti Väkeväinen \\ Laurea University of Applied Sciences (FINLAND)
}

\begin{abstract}
Research, Development and Innovation (RDI) -related work has assumed a significant role in many organizations, especially in the public sector and academic world. Research, development and innovation work is closely related to the cooperation between higher education institutions and industry, and it is usually realized in different kinds of projects and open innovation ecosystems. In such cooperation, the industry usually brings out challenges that need to be solved together with the higher education institution, which approaches the challenges from the perspectives of research, development and innovation, as well as education. This combination is both fruitful and challenging, as this kind of cooperation changes the work culture in many ways.
\end{abstract}

This presentation describes experiences gained from cooperation between a higher education institution and industry, as well as the impact of this cooperation on the academic world's working culture, which has changed a lot when compared with the traditional working culture of higher education institutions. Laurea University of Applied Sciences (hereinafter: Laurea UAS) has developed a training program to facilitate its employees' response to the changes derived from the industry cooperation. The training program has been co-created with project managers at Laurea UAS. It deals with project management and tackles the challenges found in a project manager's role. Traditionally, employees of higher education institutions are qualified teachers with expertise in their own specific field. Projects with industry partners call for many kinds of expertise and competencies, such as networking management, accountability and international communication skills, which are typically not present in teachers' everyday work. Therefore, it is important to introduce new competences for the teaching staff in order to improve the quality of projects and also to reduce variation between projects.

The presentation introduces new models for supporting project managers' work, and the presented examples are based on experiences of Laurea UAS. Laurea UAS has a strong track record in national and international RDI projects carried out in cooperation with industry. Collaboration with industry has enriched Laurea UAS's activities; real-life examples and open innovation ecosystems have offered unique possibilities to teach research and learn both for employees and students. With the support of project management training, industry cooperation has been successful and the higher education institution has gained better abilities to serve the industry more effectively.

Keywords: Cooperation between Higher Education Institution and Industry, Research, Development and Innovation (RDI), Project, Project Manager, Higher education, Training, Working Culture.

\section{INTRODUCTION}

In addition to the higher education institution's main mission, offering learning possibilities for bachelor and master level students, Laurea University of Applied Sciences is a research- and development-oriented organization that produces new competences. Laurea UAS specializes in service innovations, focusing on the regional development of the metropolitan area, and offers a multidisciplinary study environment. The working life-oriented learning method (Learning by Developing) offers a different way - with better results - to learn by working in authentic development projects together with working life representatives. The design and development of services is a shared RDI process between companies, the public sector and Laurea UAS, in which research, development, innovation and commercialization are implemented as a reflective continuum with citizens and user communities. Laurea UAS has a long history of applying a multidisciplinary, user-driven approach to regional development and RDI activities in parallel to the practice-based activity, and it efficiently involves different actors in the region, such as students, innovative start-ups, end-users, public authorities and organizations and regional policymakers in co-designing business-relevant services and social innovations within its focus areas. Implemented in close collaboration with the local actors, the joint RDI projects also create better business and 
innovation ecosystems. With regard to end-user communities, Laurea UAS is involved in establishing several physical and virtual test-bed, simulation and living lab environments for private and public actors' product and service development purposes.

Laurea UAS's experts are used to working with various society representatives, but the research, development and innovation (RDI) work has increased a lot and the demands of external funding instruments have changed the working culture. RDI-related work has changed the working culture so that teachers are increasingly collaborating with different kinds of projects, also as project managers. The skills required in project-related differ from those which teachers with pedagogical qualification are used to. Usually, teachers of higher education institutions are experts in some specific subject which is embedded in their teaching topics. But project management and networking management, accountability and international communication skills, for example, are typically not present in teachers' everyday work.

\section{THE PROJECT WORLD IS OUR FUTURE}

Asheim and Gertler [1] note that the collaboration of organizations and institutions, as well as relationships that cooperate to produce, disseminate and diffuse new and economic advances, novel knowledge and know-how, belong to the regional innovation systems. According to Pirinen [2], different organizations incorporate and share RDI functions with higher education institutions, public and private research institutes, industry, organizations and enterprises. Therefore, the core of the innovation process is the collaborative RDI system, its resources, capabilities, abilities, competencies and organizational dimensions.

It can be seen that projects are important platforms of innovation processes between higher education institutions and industry. Also, project work is a typical way of working on different kinds of tasks. Organizations are increasingly using projects to achieve their strategic objectives. According to Du, Johnson \& Keil [3], project management is a necessary element for the successful completion of most large-scale undertakings. When projects fail to achieve their desired ends, the problem is often identified as a weakness in project management.

What kind of work is that of the project manager responsible for projects? As Bredillet, Tywoniak \& Dwivedula [4] describe, one definition of project manager is the person who has some attributes to fulfill her/his role, and will demonstrate a certain level of performance. A qualified project manager is able to perform at a certain level of performance and is able to "get things done". The project manager's role is seen as multidisciplinary. According to Hyttinen [5], project management remains a professional area involving specific knowledge and skills. Project management expertise can benefit organizations, for example, by enabling them to focus on how projects contribute to their strategic goals. Project management includes the coordination and planning of resources, activities and schedules, continuous communication with interested parties and beneficiaries, the ability to estimate the project's duration and costs, as well as quality control, and results in the delivery of projects. Project management takes care of the project's objectives, methodology, communication tools, target groups, schedule, key roles of every partner and beneficiary, key responsibilities, and evaluation.

To mention some Laurea UAS's successful projects implemented in close collaboration with the industry sector, the project USCO, Using Digital Co-Creation for Business Development (2016-2018), is a good example of a national, Tekes-funded project. The aim of USCO is to develop business through digitalization, which has an influence on value creation for services and processes across industries and public organizations. The main focus of the USCO project is to develop Finnish companies' capabilities of utilizing digitalization [6]. The Horizon2020-funded international project WeLive (2015-2018) transforms the current e-government approach by facilitating a more open design, production and delivery model of public services, leveraging on the collaboration between public administrations (PAs), citizens and entrepreneurs. Project managers in these projects have abilities of working in a multidisciplinary project consortium, which demands a large scale of skills related to project management [7].

Laurea UAS has put lots of effort into enhancing the project managers' competencies, because without qualified project managers, it would be impossible to handle ongoing projects successfully and the cooperation with industry would end quickly. This is the reason why Laurea finds it important to take care of project managers' skills. 
As mentioned earlier, the working culture also in higher education institutions has changed during the last decade. The ways of learning and teaching have changed from traditional teacher-led teaching to student-centred learning [eq. 8]. The pedagogical development at Laurea UAS has focused towards the new role of the teachers: the teacher is a guide, a senior colleague, a coach and the coordinator of the projects with industry $[9,10]$. Two decades ago teachers could concentrate on providing information for the students and guiding their professional development. Today, teachers need to train the students to develop complex challenges in the working life and, at the same time, manage the projects and the large national or international networks. Competence requirement differs a lot from the competences needed earlier.

\section{THE ANSWER IS COMPETENCE}

This article focuses on a project manager training program which Laurea UAS has developed for its workers to increase the competence of project managers working at Laurea UAS and in projects in which Laurea UAS is involved. The training program was created in 2016 in cooperation with Laurea UAS's project managers. The development of the training started with ten qualitative interviews in which project managers were asked to describe their work as a project leader and manager, the challenges they faced in their daily work, and their wishes regarding the new training program. The interview response data was used as a background material in workshops, where the content of the training program was designed jointly with project managers and other project experts.

The aim of the "Laurea Certified Project Manager training" was to help Laurea UAS's project managers lead their projects better and to clarify the project manager's work. According to Hyttinen [5], project management has become an important competency in many organizations. Project managers are often involved in managing one or more projects and, as projects usually also include collaborative projects with academic institutions, private enterprises and government organizations, project managers are in touch with many kinds of organizational cultures. This means that there are many roles with different interests in the project and project management practices.

According to Bredin \& Söderlund [11], companies that have invested in project management training are more aware of the requirements needed in project managers' tasks and more willing to support the development of individual project managers. Such companies saw project managers' careers as multidimensional entities, in which the work is affected by the external labor market, clients and external institutions, as well as the nature of production. Therefore, projects differ from each other, especially in their degrees of clarity. These conditions are in line with career models: different career models are applied to different kinds of project managers.

Raminez [12] has presented a project-based entrepreneurship model that shows the influence and relationships of a project manager's characteristics in the entrepreneurial process [12]. Project managers have individual characteristics, such as competences and personality features, which may influence the exploitation and discovery of entrepreneurial opportunities and projects. The project manager could be seen as an "expert" in utilizing different opportunities or projects, rather than as a specialist of discovering them. The idea that project managers could be involved in a different projects launches the idea that the type of project may effect on the required set of project manager's characteristics. Different types of projects should be managed in different ways [13].

\section{CERTIFIED PROJECT MANAGER TRAINING AS THE RESULT}

Studies have shown that such fields as leadership, strategic management, psychology, and entrepreneurship are typical competencies of good project managers [12]. Similar results were found in Laurea UAS's interviews and workshops arranged for the purpose of training content planning, as well as in findings of agile project management. Laurea developed a training program to help its employees respond to the changes derived from industry cooperation. The Laurea Certified Project Manager training tackles the challenges found in a project manager's role.

Most of the project managers at Laurea UAS are teachers, who work as senior or principal lecturers at the same time as they work as project managers in nationally or internationally funded projects. Hence the teachers are multitaskers. Teachers manage both student groups and the networks of partners. The requirements of various competences are high.

The training started in autumn 2016. It contains 9 days of contact learning, each focusing on different topics related to the project managers' work. The training program started with an introduction of 
project managers' role in projects and tasks belonging to their responsibility. At the moment Laurea UAS has approximately 67 ongoing projects so it is important to follow processes and instructions at Laurea UAS to have project management work effective.

Another topic in training is network management, which is seen as an important skill in project managers' work. Networks between people play an essential role in creating new ideas and projects. When applying RDI funding, combining different competencies is important and networks are typically useful in finding the required expertise. Project partners create a network in which the roles of participants are built according to the targets. The project manager benefits from knowing how to lead networks and how to get added value from the network.

Agility is also seen as an important ability for the project manager. Comparing to the traditional project management, agile approach helps for example in organizing meetings effectively and planning iteratively with a smaller set of requirements.

One important topic in the training deals with the solutions to the challenges in projects and question why do projects fail? Participants view typical challenging situations and co-create solutions for example to the situation of having too few resources working on too many projects at the same time or what to do when project manager finds out that budget and resource estimates are wrong.

Communication and marketing are also part of the training program as communication, oral and written expression are the most needed skills to be in touch with project consortium and beneficiaries. A project manager needs to be both a clear communicator and a good marketer. Otherwise the project manager needs someone else to take care of these tasks to make sure that project consortium knows how to fulfill project goals.

Integration of RDI and teaching is essential for Laurea UAS's pedagogical approach Learning by Doing. Lecturers as project managers have to create pedagogical approaches to their projects in order to integrate bachelor and master level students and projects. Training program offers tools for that.

We consider the good management as the relevant topic to renew the teachers' work. There is a need for management and leadership activities that arise from the strategic choices. On the other hand, there is a huge need for the teachers, to save their freedom to decide the methods how they work and how to create new competence. We have a challenge in management and leadership when the freedom and the strategic goals are set parallel. [eq. 14]. The leadership culture has become more employee centric. The managers and directors are rather coaches and enablers than commanders and controllers. The meaning of leadership is to enable the best possible environment to work [eq. 15]. Project management training program deals with leadership issues as well.

In academic research, there is also a need for higher efficiency, and the impact of the research is becoming more and more important in the future. We found out that by introducing new kinds of concepts for increasing competence in academic research projects, we can tackle both of these challenges.

In companies' product and service development, there are many parameters to be improved, and one of those is time-to-market. If companies can introduce products and services faster than their competitors, they will get competitive advantage. Companies are using different methods in order to introduce the right products/services in to customers. Those methods include, for example, agile product development, lead production and product development. Similar methods can also be used in research projects in the academic environment. We wanted to introduce these methods also to the project managers' toolkit and their way of working.

\section{CONCLUSIONS}

This paper has described new models of promoting a project manager's work, as well as cooperation between higher education institutions and industry. The examples presented herein are based on experiences of Laurea University of Applied Sciences. Thomas and Mengel [16] argued that complexity, uncertainty and chaos play an increasingly important role in projects and project environments. Therefore, it is extremely important for a successful organization to take care of its employees and their ability to manage complexity and chaos which can be caused by participating different kinds of projects.

There are several kinds of project management training available commercially. We explored those but they didn't fulfill fully the needs of the RDI projects carried out in the academic research and development environment. Also, we found out that the level of commitment to our training was pretty 
high and the feedback on the training has been positive. Employees at Laurea UAS appreciated the fact that their wishes and needs were taken into consideration and the training tackles actual challenges faced by the participants. So, the participants had a real possibility to influence the training content and this increases their motivation.

Laurea Certified Project Manager program's trainers have received positive feedback, because all of them are experts at Laurea UAS and we found out that it has been a good choice to build the training program so that all participants can make notice of their colleagues' knowledge and skills. Furthermore, the training sessions have been interactive, which encourages participants to share their own experiences. Even though the training is new, Laurea UAS has participated in RDI-related work for years and it already possesses lots of experience in and knowledge of successful project management. Paying attention to the participants' experiences adds value to the whole training, for example so that new project managers can benefit from their more experienced colleagues' cases. The effectiveness of project management training have been researched at the same time with implementing the training program and research will offer an important information of first year's training. Collaboration between Laurea UAS and industry changes and in few years we might need other topics to train project managers.

Cooperation between higher education institutions and industry is important. Eventually, this cooperation creates the basis of universities at applies sciences in Finland, as the aim is to create sustainable and internationally competitive products of new knowledge together with the region and its industries and other organizations. Moreover, universities of applied sciences are meant to serve their region's working life and carry out RDI work to guarantee the region's competiveness and attractiveness. Taking care of employees' competences lays a solid foundation for different kinds of successful cooperation.

\section{REFERENCES}

[1] Asheim B.T. \& Coenen L. (2005) Knowledge bases and regional innovation systems: Comparing Nordic clusters. Research Policy 34, 1173-1190.

[2] Pirinen R. (2013) Towards Regional Development by Higher Education Institutions. An empirical study of a University of Applied Sciences. University of Oulu. Juvenes print. Tampere.

[3] Du S., Johnson R. D. \& Keil M. (2004) Project Management Courses in IS Graduate Programs: What is Being Taught? Journal of Information Systems Education, Vol. 15(2).

[4] Bredillet, C., Tywoniak S. \& Dwivedula R. (2015). What is a good project manager? An Aristotelian perspective. International Journal of Project Management Volume 33, Issue 2, Pages 254-266.

[5] Hyttinen, K. (2017). Project Management Handbook. Laurea Julkaisut I Laurea Publications 76.

[6] USCO -project's home page: http://www.uscoproject.fi/usco-project.html. Assessed 18.1. 2017.

[7] WeLive -project's home page: http://welive.eu/. Assessed 18.1.2017.

[8] Nurkka, P. \& Pääskyvuori M. (2014) Designing a Multi-Purpose Office through Learning by Developing. EuroFM Journal. International Journal of Facilities Management. EuroFM publications. Naarden.

[9] Raij, K. (2007). Learning by Developing. Laurea Publications A-58. Vantaa.

[10] Ahonen, O., Meristö, T., Ranta, L. \& Tuohimaa, H. (2014). Project as a Patchwork Quilt - from Study Units to regional Development. In the Publication Katariina Raij (ed.) Learning by Developing action model. Laurea Publications. Espoo: Grano.

[11] Bredin, Karin \& Söderlund Jonas (2013). Project managers and career models: An exploratory comparative study. International Journal of Project Management 31.

[12] Raminez, Andres (2013) Project manager's characteristics influence in the entrepreneurial process: A project-based entrepreneurship model. DRUID Academy 2013 at Comwell Rebild Bakker, Rebild/Aalborg

[13] Dvir, D. O. V., Sadeh, A., \& Malach-Pines, A. (2006). Projects and Project Managers: The Relationship Between Project Managers' Personality, Project Types and Project Success. Project Management Journal, 37(5), 36-49. 
[14] Niinistö-Sivuranta, S., Nurkka, P. \& Lahti, J. (2015). Kuka varmistaa osaamisen? In the publication Sirén, Hannu, Hannu Kotila, and Kimmo Mäki. 21 Tapaa Tehostaa Korkeakouluopintoja. Helsinki. Haaga-Helia ammattikorkeakoulu.

[15] Vanhanen-Nuutinen, L., Töytäri-Nyrhinen, A. \& Mäki, K. (2013). Ammattikorkeakoulun opetushenkilöstön osaaminen ja osaamisen kehittäminen. In the Publication L. VanhanenNuutinen, A. Töytäri-Nyrhinen \& K. Mäki (ed.) Kiviä ja keitaita - Ammattikorkeakoulutyö muutoksessa. Haaga-Helia. Vantaa: Multiprit, 25 - 29.

[16] Thomas, J., Mengel, T. (2008). Preparing project managers to deal with complexity - Advanced project management education. International Journal of Project Management 26. 304-315. 